\title{
A New Multiteam System (MTS) Effectiveness Model
}

\author{
John Turner ${ }^{1} \mathbb{D}$, Rose Baker ${ }^{1, * \mathbb{D}}$, Zain Ali ${ }^{1}$ and Nigel Thurlow ${ }^{2}$ \\ 1 Department of Learning Technologies, University of North Texas, Denton, TX 76207, USA; \\ john.turner@unt.edu (J.T.); zain.ali@unt.edu (Z.A.) \\ 2 The Flow Consortium, Celina, TX 75009, USA; nigelthurlow@gmail.com \\ * Correspondence: rose.baker@unt.edu
}

Received: 24 February 2020; Accepted: 15 April 2020; Published: 19 April 2020

\begin{abstract}
Team effectiveness models in the literature are primarily concentrated on traditional teams, with few involving the multiteam system (MTS) level of analysis in the model. Teams achieve their goals by managing both teamwork (e.g., interpersonal, effective, motivational, cognitive) and taskwork (e.g., strategy, goal setting, project management) activities. When MTSs are involved, multiple teams manage their own teamwork and taskwork activities, while leadership must be in place to coordinate these activities within and between teams in order to achieve the organization's goal (the MTS's goal). This research study conducted a systematic review of current team effectiveness frameworks and models. A narrative-based method for theorizing was utilized to develop a new MTS team effectiveness framework. This research contributes to the MTS literature by providing a new formula for team effectiveness at both the team level (team effectiveness formula) and the MTS level (MTS team effectiveness formula). This research aids managers, practitioners, and researchers by providing a tool that accounts for all levels and temporal processes.
\end{abstract}

Keywords: multilevel; multiteam systems; structure; team; team effectiveness; teamwork

\section{Introduction}

Team effectiveness takes on many meanings in the literature and has often been mistaken to be equated with team performance [1]. There is no standard definition or measure for team effectiveness in the literature [1]. In general, team effectiveness can be defined as the point at which the team's processes align with external task demands [2] and can be considered optimized when the desired outcome has been achieved (value delivered to the customer) [3]. Team effectiveness is portrayed as a function of "task, group, and organization design factors, environmental factors, internal processes, external processes, and group psychosocial traits" [4] and should not only be confined to team performance outcome measures. Team performance relates to what teams do, relating to both behavioral and traditional outcome measures that are judged by others [2]. Team effectiveness, from a behavioral perspective, focuses on "coordination, cooperation, and communication; team skill competencies and performance functions; and regulation, performance dynamics, and adaptation" [2] (p. 95), whereas traditional performance measures view a team's outcome by some predetermined standard, typically in the form of some form of tangible output or product (e.g., productivity, quality, quantity, time) [5]. Team effectiveness encompasses a team's outcome (behavioral and performance-related measures) as well as the interactions (teamwork) and processes (teamwork and taskwork) used to produce the outcome. Team effectiveness is holistic in that it accounts for the team's performance, teamwork and taskwork processes in order to achieve the team's goal [6].

Recent developments in team research have led to advancements in new theories, measures, and methods that view teams as being dynamic, multilevel, and complex dynamic systems $[5,7,8]$. While research within the field of team science has been growing, researchers are calling for further 
advancements within the team effectiveness field of study [7]. In terms of multilevel systems, team researchers are calling for advancements in multilevel team theories and the analysis techniques [8] that account for temporal factors [8].

Teams are complex adaptive systems that are part of a larger network or system; researchers need to extend existing linear theories to develop more nonlinear theories that address teams as complex adaptive systems within a larger network system (e.g., organization, institution) [5]. Larger network systems involve multiteam systems (MTS) that coordinate activities among teams and between MTSs. The concept of MTSs in the workplace is becoming more common than it was just 10 years ago. This expansion of teams and MTSs in the workplace is partially a response to today's complex environment, globalization, and technological advancements [9]. These new organizational structures (team-based organizations, virtual organizations and matrix organizations) include "tightly coupled constellations of teams" [9] (p. 4), also known as MTSs. Calls have been made by researchers to expand research on teams that include MTSs as a new level of analysis [10-12] and to reconfigure current theories, frameworks, and models so that they accommodate this new level of analysis.

The current study addresses these calls by identifying the components of team effectiveness for teams and for MTSs from the literature, while providing a basic team effectiveness formula for both individual teams and for MTSs. This study also provides a framework for team effectiveness characteristics at each level of analysis (individual, team, multiteam system). In this framework, individuals make up a team, while multiple teams operating interdependently toward both proximal (team goals) and distal goals (MTS goal) make up an MTS, ultimately achieving the organization's goal. The current study also addresses how this team effectiveness framework can be utilized for training and evaluating teams in today's workplaces and by researchers to advance the understanding of team effectiveness in organizations.

Currently, there is no multilevel team effectiveness framework that accounts for the MTS level of analysis. While much work has been done regarding team effectiveness, the research has not fully addressed this new level of analysis in current team effectiveness models. This is evident in the following: "Although much work has been completed on the attributes that promote effective interdependence and coordination within teams ..., the findings of such research do not translate easily and isomorphically to the MTS level" [9] (p. 25). The current study provides a team effectiveness framework that includes three levels of analysis (individual, team, MTS).

\section{Method}

For the current study, we conducted a systematic review of the different team effectiveness frameworks from highly cited team effectiveness review articles and book chapters. A search for articles was conducted within Academic Search Complete EBSCOhost, JSTOR, Science Direct, and Web of Science. The following keywords were used to search the full text, ("team effectiveness" AND individual OR "multiteam system" OR team AND "systematic review") and ("team effectiveness" AND individual OR "multiteam system" OR team AND "integrated literature review"), within Academic Search Complete EBSCOhost to yield over 1000 academic journal articles and book chapters. Because the focus was on multiteam systems, a new search was conducted using "team effectiveness" AND "multi team" OR "multiteam" within the databases. The number of articles and book chapters from each of the databases were, for Academic Search Complete EBSCOhost: 22, JSTOR: 34, Science Direct: 15 (review articles), and Web of Science: 131 (two were identified as highly cited). The team reviewed the articles and selected eight articles related to team effectiveness, 12 articles related to team process models and emergence, and six articles related to common team-based models. Data from these review articles and book chapters were collected and synthesized into a common framework that accounted for each level of analysis (individual, team, MTS). The initial search was conducted to include the literature from 1998 to 2018; however, as the study progressed, newer, more relevant studies on team effectiveness and MTS were included to keep the study current. The search reports include the newer literature. 


\section{Team Effectiveness}

Team effectiveness takes on many meanings, with no formal definition or measure [1]. This could be because team effectiveness is contextual and can vary from one situation to the next. In the literature, team effectiveness has been defined as the point at which "team processes are aligned with environmentally driven task demands" [2] (p. 78). Other views of team effectiveness refer to the output of team behavior [13], which can be optimal when the right 'enabling conditions' take place [14]. Studies have highlighted that teams with team members showing proficiency in teamwork knowledge demonstrated higher task proficiency, and overall team effectiveness [15]. Team effectiveness research has focused on the who, how, and what that leads the team to its goal, measured as the team's performance or outcome [16], though this approach often misses the teamwork aspect of team effectiveness.

In designing new teams, there are six enabling conditions that need to be considered for a highly effective team:

1. Creating a real team (rather than a team in name only);

2. Specifying a compelling direction or purpose for the team;

3. Putting the right number of the right types of people on the team;

4. Specifying clear norms of conduct for team behavior;

5. Providing a supportive organizational context;

6. Making competent, team-focused coaching available to the team [17] (p. 49).

Unfortunately, most teams have already been put together in one way or another (accidentally, randomly, systematically) and most organizations, managers, and researchers need to determine a team's effectiveness in a post-hoc manner. Three dimensions have been identified as being associated with highly effective teams. These dimensions could, and have, been used to assess a team's effectiveness:

1. The productive output of the team (that is, its product, service, or decision making) meets or exceeds the standards of quantity, quality, and timeliness of the team's clients-that is, of the people who receive, review, and/or use the output;

2. The social processes the team uses in carrying out the work enhance members' capability to work together interdependently in the future;

3. The group experience, overall, contributes positively to the learning and professional development of individual team members [17] (pp. 37-39).

These three dimensions can be summarized as the team's output or performance (item 1), the intragroup dynamics that make up the social interactions of the individual team members (item 2), and team members' past experiences, current experiences, and learning, which can be applied to future teamwork activities (item 3). Ultimately, a team's final product is a factor of the team's intergroup dynamics and the team member's ability to learn and develop together based on their shared cognitions and shared learning experiences. Performance is generally a measure of the team's output and is often the only measure that matters to management. However, delivering value to the customer should become an essential component in any team effectiveness model. Teams must acknowledge external stakeholders who may fall into the customer category: "anyone outside of the team that has a value stake in the team's functioning" [5] (p. 20). The team represents the process that consists of teamwork and taskwork. The inputs to teamwork and taskwork are generally represented by the social, intragroup, cognitive, and learning functions (emergent states), as well as task-dependent characteristics, each driving the teamwork and taskwork processes.

Team processes can be further characterized into three temporal phases: transition, action, and interpersonal [18]. Here, team process is defined as the team members' actions, which transfer inputs into outcomes via cognitive, verbal, and behavioral activities (emergent states), directed toward taskwork to achieve the team's goal [18], or how "teams achieve their outcomes" [19] (p. 812). Thus, 
teamwork processes orchestrate taskwork activities to be conducted by team members to achieve the team's goal [18].

\subsection{Team Effectiveness Process-Type Models}

Team effectiveness process models begin with McGrath's input-process-output (I-P-O) framework $[8,16]$. By utilizing a system theory framework, inputs are antecedent factors that contribute to the generation of the process which eventually produces an outcome. In relation to viewing teams from the I-P-O perspective, antecedents relate to factors that either enable or prevent team member interactions [16]. Processes relate to the team and how the antecedents are combined and transformed into outcomes, the "by-products of team activity" [16] (p. 412). Some criticism relating to the I-P-O framework began to surface indicating that the I-P-O framework was insufficient for teams in three key areas $[8,16]$ :

- Mediational factors, which intervene and transmit the influence of inputs to outcomes, are not processes;

- The I-P-O framework limits research by implying a single-cycle linear path from inputs to outcomes;

- The I-P-O framework tends to suggest a linear progression of main effect influences, proceeding from one category (I, P, or O) to the next [8] (p. 520).

These deficits led to a new framework, which included emerging states, defined here as "constructs that develop over the life of the team and impact team outcomes" [8] (p. 520). This produced the input-mediator-output-input (IMOI) framework, replacing the process with a mediator in order to represent a broader coverage of emerging states. The input at the end represents the return to the input phase as a form of feedback that identifies the framework as being iterative. The removal of the dashes between the letters (I-P-O) removes the connotation that the linkages may not necessarily be linear [8].

In viewing the team process from the perspective of complexity theory, Turner and Baker [20] presented a new framework that accounted for the property of emergence. Emergence, from complexity theory, is a result of "interaction, tension, and exchange rules governing changes in perceptions and understandings" [21] (p. 2). Accounting for emergence, and positioning teams as multilevel and complex adaptive systems, Turner and Baker [20] presented the input-process-emergence-output (I-P-E-O) model. Emergence occurs from the interactions that take place within the team processes, which, in turn, lead to new and innovative methods of achieving the team's goal (output).

Other team effectiveness models accounted for the different levels of analysis under the input, while acknowledging emergent states with the team processes. The inputs included individual-, team-, and organization-level factors with both the team processes and emergent states combined, and the outcomes last, with a feedback mechanism that returns to the inputs [22]. This team effectiveness framework is an extension of the I-P-O model, addressing multiple levels at the input stage while providing feedback mechanisms, highlighted as the IPOI framework.

In terms of MTSs, multiteam effectiveness has been considered by three primary attributes: compositional, linkage, and developmental [9,12]. Compositional attributes represent the demographics and characteristics of component teams [9], identifying both the individual team and MTS characteristics. Linkage attributes identify the connections and communication channels between teams, whereas developmental attributes look at how MTSs develop and mature over time [9,12]. When MTSs are involved, multiteam effectiveness is accomplished, in part from "the ability of component teams to integrate their actions successfully in response to the kinds of environmental events [complexity] that instigate their formation" [9] (p. 25).

Viewing team processes as being multidimensional, in which different processes operate at different points in time, there have been calls for different team member interactions to take place at various times during a team's tenure. Rather than viewing emergent states (e.g., team members' attitudes, values, cognitions, motivations), Marks, Mathieu and Zaccaro's [18] temporal taxonomy 
concentrated on team process dimensions. Whereas teamwork and taskwork occur sequentially during a team's tenure, the two processes remain separate, while also being dependent upon one another. These teamwork/taskwork processes continue, ultimately, "until teams reach more distal team outcomes" [18] (p. 358). These distal outcomes are often viewed as being the organization's goal, however they could easily be the MTS's goal in an MTS structure. The temporal taxonomy model builds upon the I-P-O model and assigns episodes (periods of performance), identified as three process dimensions: transition phase processes, action phase processes, and interpersonal processes [18].

\section{Emergent States}

For teams to be effective, it is commonly agreed that teams must engage in both taskwork and teamwork processes $[16,23]$. Taskwork is associated with specific functions required of team members in order to complete their tasks and contribute to the team's goal, whereas teamwork relates to the interaction between team members [16] involving the "shared behaviors, attitudes, and cognitions" [23] (p. 16) associated with accomplishing the team's goal. Taskwork has been categorized as consisting of "task complexity, task interdependence, and environmental uncertainty" [13] (p. 501). Teamwork has been divided into three psychological facets, or emergent states: effective/attitudes, behavioral/motivational, and cognitions $[2,23,24]$. These two effectiveness processes work hand-in-hand, as depicted in the following explanation: "A dynamic, shifting, and complex environment creates commensurate team task demands that members have to resolve though a coordinated process that combines their cognitive, motivational/effective, and behavioral resources" [2] (p. 78).

Attitudes have been identified as internal states that interfere with interactions among other team members, "such as mutual trust, cohesion, and collective efficacy" [23] (p. 16). Other effect measures might include contagion, which identifies with how one person's moods and emotions transfer to other team members [2]. Behavioral facets relate to the required processes for team members to engage in teamwork [23]. Behaviors can be loosely defined as those that are relevant to goal attainment [16] (p. 416), including: "coordination, cooperation, and communication; team skill competencies and performance functions; and regulation, performance dynamics, and adaptation" [2] (p. 95). Cognitive states represent knowledge structures that are shared among team members, such as collective perception, information acquisition, knowledge organization [2], and the representation of knowledge among members [23]. Cognitive structures "enable team members to organize and acquire information necessary to anticipate and execute actions" [2] (p. 83).

\subsection{Common Team-Based Models}

The following sections highlight some of the more common team effectiveness frameworks or models for teams and MTSs.

\subsubsection{Ilgen et al. (2005)}

In a review of the literature, Ilgen, Hollenbeck, Johnson and Jundt [8] identified mechanisms that mediate team inputs into outcomes in relation to the IMOI framework. Mediators, or emerging states, were categorized in the following manner: the Forming Stage was represented by the IM phase of the IMOI framework (e.g., trusting, potency, safety), the Functioning Stage was represented by the MO phase of the IMOI framework (e.g., bonding, managing diversity of membership), and the Finishing Stage was represented by the OI phase of the IMOI framework (e.g., planned, unplanned, task failure) [8].

\subsubsection{Marlow et al. (2018)-MTSs in Healthcare}

From a review of the healthcare literature on team performance measures, Marlow, Bisbey, Lacerenza and Salas [25] identified 70 different health care team performance measurements and compiled a total of 31 assessed competencies. Teamwork assessments were categorized into attitudes (e.g., team orientation, psychological safety, cohesion), behaviors (e.g., performance monitoring, 
mission analysis, motivation of others), cognitions (e.g., cue-strategy associations, shared mental models), and general teamwork, with an understanding of multiteam system (MTS) couplings [25].

\subsubsection{Magpili and Pazos (2018)—SMT}

In self-managed teams (SMT), Magpili and Pazos [22] identified a number of individual-, team-, and organization-level factors that led to SMT performance. Self-managed teams are similar in nature to collective and shared leadership designs, as in many team-based operations, and are especially relevant in organizations that have flattened their hierarchical structures [22]. An SMT is defined as "a group of individuals with diverse skills and knowledge with the collective autonomy and responsibility to plan, manage, and execute tasks interdependently to attain a common goal" [22] (p. 4). The factors that lead to SMT performance include individual-level variables (e.g., autonomy, leadership, self-management skills), team-level variables (e.g., external leadership, peer control, diversity), and organization-level variables (e.g., corporate culture, organizational structure, resources) [22].

\subsubsection{Zaccaro and Shuffler-MTS Effectiveness}

Zaccaro, Marks, and DeChurch's [9] model of multiteam system effectiveness includes the compositional, linkage, and developmental attributes (see also [12]). These attributes serve as antecedents to both multiteam-intrateam (within) and interteam (between) processes that lead to an effective MTS [9]. Compositional attributes refer to how teams are composed (e.g., size and number teams, team boundaries, temporal orientation), linkage attributes identify how component teams are connected (e.g., hierarchical arrangement, power distribution, network), and developmental attributes relate to how MTSs evolve over time (e.g., genesis, direction of development, transformation of MTS composition) [9].

\subsubsection{Shuffler et al. (2015)—MTS Intra- and Inter-Team Processes and Outcomes}

Inter- and intra-team processes and outcomes, as identified by Shuffer et al. [12], include attitudes (e.g., cohesion, social identity, trust), behaviors (e.g., conflict, interpersonal behaviors, transition behaviors), cognitions (e.g., shared mental models, transactive memory system) and performance outcomes (e.g., goal attainment, innovation, team satisfaction) that have been represented in the recent literature related to MTSs [12]. Their research highlighted which emerging states, either via processes or outcomes, were associated with intra-team dynamics (within team), inter-team dynamics (between teams), or both [12].

\subsubsection{Marks (2011) - Taxonomy of Team Processes}

Team processes are multidimensional and involve both teamwork and taskwork operating at different stages of the team's formation, while also being connected sequentially. Team processes are described by Marks, Mathieu and Zaccaro [18] as being: "multidimensional ... teams use different processes simultaneously and over performance episodes in order to multitask effectively. Some processes transpire more frequently in action phases and others in transition periods" (p. 362). Team processes are categorized into three process dimensions: transition phase processes (mission analysis formulation and planning, goal specification, strategy formation), action phase processes (monitoring progress toward goals, systems monitoring, team monitoring and backup responses, coordination activities), and interpersonal processes (conflict management, motivation and confidence building, effect management) [18].

\section{MTS Team Effectiveness}

At the team level, teams are viewed as being multilevel systems in that they operate at two levels (individual, team), while also being embedded in a larger organizational system [16]. This perspective has been supported by the literature in looking at teams, team effectiveness, workflow interdependence, and virtuality [26], while others identified teams as being multilevel and dynamic [27]. 
When viewing an MTS, it is necessary to account for individual team members (individual level) in each team (team level) that make up the MTS (MTS level) within the larger organization (organization level). This conceptualization, showing how a team operates within a larger multilevel system, was provided by Kozlowski and Ilgen [2]:

We adopt a more contemporary perspective that has evolved over the last decade, which conceptualizes the team as embedded in a multilevel system that has individual, team, and organizational-level aspects; which focuses centrally on task-relevant processes; which incorporates temporal dynamics encompassing episodic tasks and developmental progression; and which views team processes and effectiveness as emergent phenomena unfolding in a proximal task- or social context that teams in part enact while also being embedded in a larger organization system or environmental context. (p. 80)

This conceptualization, of teams embedded in a larger multilevel system, has been supported by the literature. For example, Marks et al. stressed the importance of taking a multilevel perspective when viewing teamwork processes in an MTS, because "team-focused process-performance relationships may not be homologous across levels" [28] (p. 970). The field of team science has expanded into the realm of MTSs, introducing a new level of complexity, suggesting that teams in organizations now be characterized as consisting of individuals within teams, in MTSs, as part of a larger organizational system.

Teams are also characterized as complex adaptive systems (CAS) [20,29]. Teams are viewed as being complex, "embedded in a hierarchy of levels and characterized by multiple, bidirectional, and nonlinear causal relations" [29] (p. 98). If today's teams are viewed as CAS, then adding a new level of analysis, an MTS level of analysis, introduces a new level of complexity, making MTSs hyper-complex adaptive systems (H-CAS).

\section{Team Effectiveness Formula}

Team effectiveness (TE) includes the components of teamwork (TW), task work (TK), outcome or performance $(P F)$, and value provided to the customer $(C V)$. This results in the following team effectiveness formula, Formula (1):

$$
T E=T W+T K+P F+C V
$$

The components of team effectiveness are depicted in a concept map in Figure 1 . These elements-teamwork, task work, customer value, and performance-are measured at level 1 in the multilevel system, the team level.

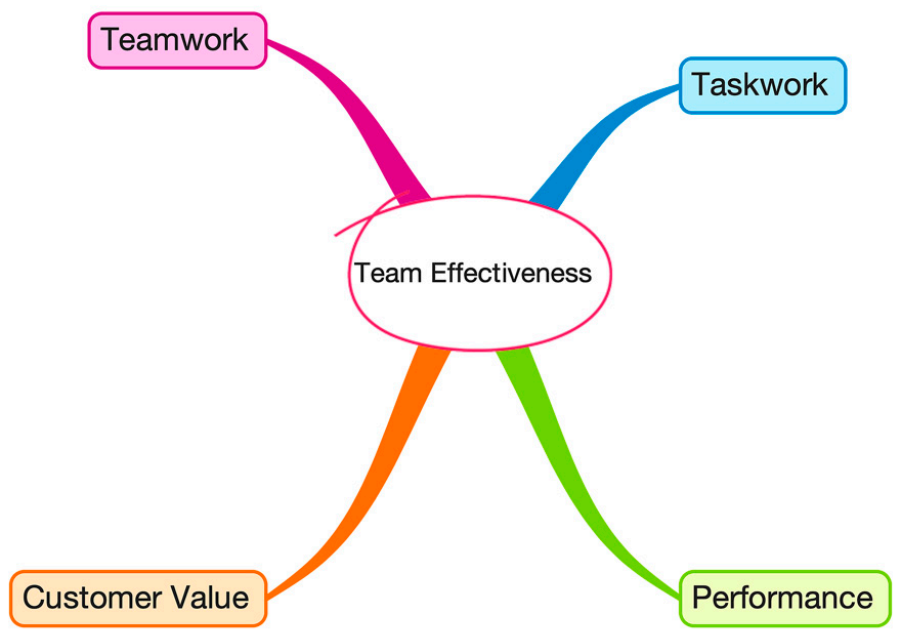

Figure 1. Team effectiveness components. 
When incorporating Marks, Mathieu and Zaccaro's [18] team temporal processes (transition phase processes $(T P)$; action phase processes $(A P)$; interpersonal phase processes $(I P))$ into Formula (1), we get the following revised team effectiveness formula, Formula (2):

$$
T E=(T W+I P)+T K(T P+A P)+P F+C V
$$

Team effectiveness, as depicted in Formula (2), is composed of: teamwork (TW), interpersonal phase $(I P)$ processes; taskwork $(T K)$ as a function of transition $(T P)$ and action phase $(A P)$ processes; performance $(P F)$ composed of quality, quantity, or some time characteristics; and customer value $(\mathrm{CV})$, which involves external stakeholders and team member experiences. An expanded concept map of the team effectiveness components is depicted in Figure 2. The branches of the team effectiveness components reveal the possible complexity of inputs for team temporal processes. The transition and action phase processes influence the function of the taskwork component of team effectiveness. The interpersonal phase process influences the teamwork component. Elements used to measure customer value and performance highlight necessary team member interactions, such as team member commitment, satisfaction, and timely task completion.

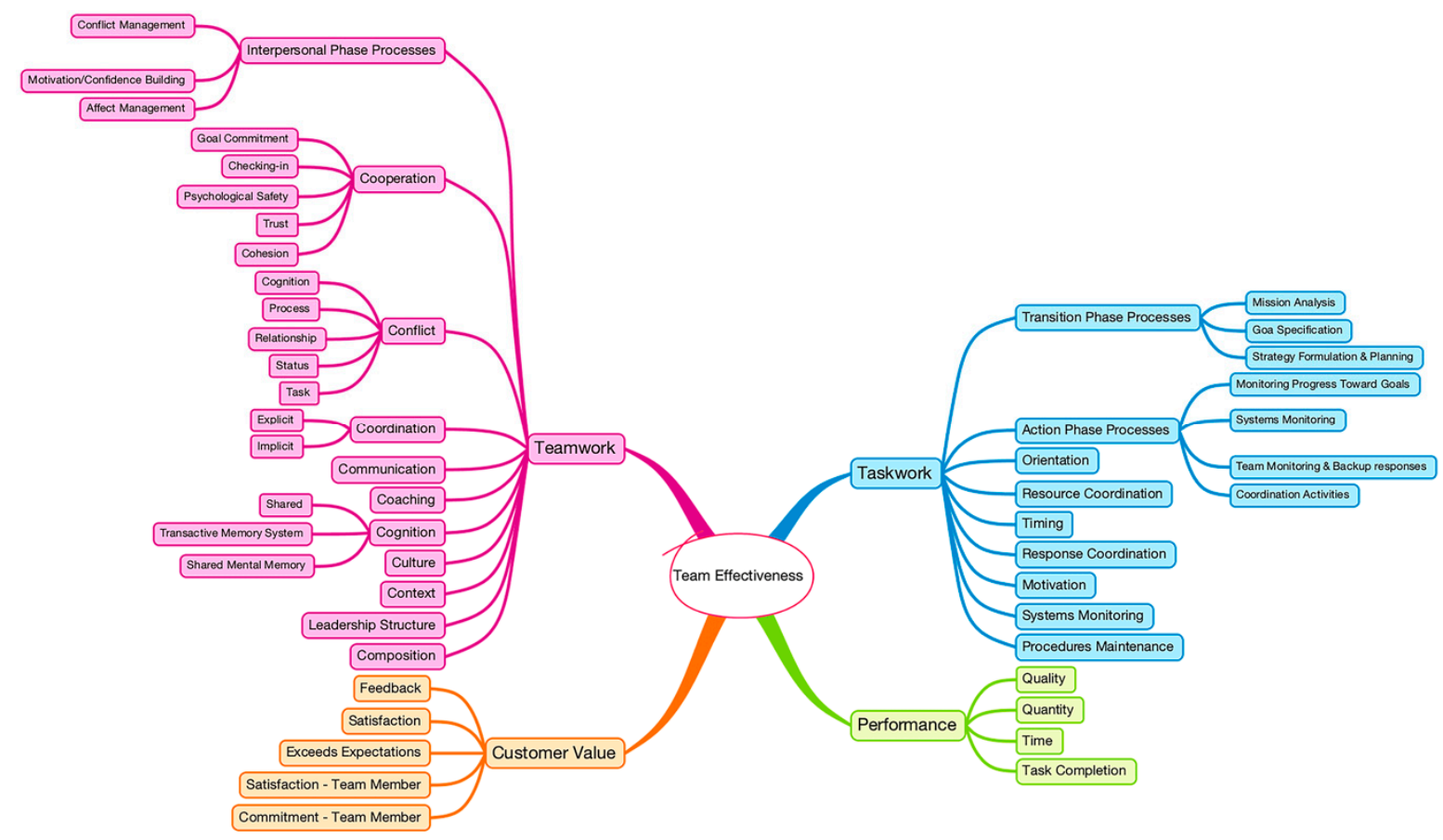

Figure 2. Team effectiveness components expanded.

Team effectiveness components that have been identified from the previous team effectiveness frameworks (from the literature discussed in the previous sections) have been compiled into a composite table (Table 1) for each of the components of the team effectiveness formula. This table identifies the components that are essential when developing training and/or evaluating the effectiveness of individual teams. 
Table 1. Team effectiveness components.

\begin{tabular}{|c|c|c|c|}
\hline$(\mathrm{TW}+\mathrm{IP})$ & $\mathrm{TK}(\mathrm{TP}+\mathrm{AP})$ & PF & $\mathrm{CV}$ \\
\hline Teamwork & $\begin{array}{l}\text { Taskwork (transition phase } \\
\text { processes and action phase } \\
\text { processes) }\end{array}$ & Performance & $\begin{array}{l}\text { Customer value (internal, } \\
\text { external, or both) }\end{array}$ \\
\hline Team composition $[9,12,23]$ & Orientation $[6,22]$ & Quality [12] & Feedback $[18,22]$ \\
\hline Cooperation $[2,23,30]$ & $\begin{array}{c}\text { Resource } \\
\text { coordination }[9,12,18,22]\end{array}$ & Quantity $[9,12]$ & Satisfaction $[3,5]$ \\
\hline Goal commitment $[22,25,31]$ & Timing $[9,12,22,25,31]$ & Time $[9,12]$ & Exceeds expectations [22] \\
\hline Checking-in [23] & Response coordination [8] & Task completion [6] & $\begin{array}{l}\text { Satisfaction of team } \\
\text { members }[8,12,22]\end{array}$ \\
\hline Psychological safety $[8,12,25,31]$ & Motivation $[18,22]$ & & $\begin{array}{c}\text { Team member } \\
\text { commitment }[8,9,12,18,22]\end{array}$ \\
\hline Trust $[6,8,12,25,31]$ & Systems monitoring $[8,12]$ & & \\
\hline Cohesion $[12,18,25,31]$ & Procedures maintenance [32] & & \\
\hline Conflict $[12,18]$ & Transition Phase Processes & & \\
\hline Cognition conflict [18] & $\begin{array}{c}\text { Mission } \\
\text { analysis }[9,12,18,22,25,31]\end{array}$ & & \\
\hline Process conflict [18] & Goal specification $[8,9,12,18,22]$ & & \\
\hline Status conflict $[9,12]$ & $\begin{array}{l}\text { Strategy formulation and } \\
\text { planning }[8,12,18,22]\end{array}$ & & \\
\hline Task conflict [18] & Deliberate planning $[8,12,18]$ & & \\
\hline Coordination $[9,12,18,25,31]$ & Contingent planning $[8,12,18]$ & & \\
\hline Explicit $[23,33]$ & $\begin{array}{c}\text { Reactive strategy } \\
\text { adjustment/adaptability }[6,8,18]\end{array}$ & & \\
\hline Implicit [33] & Action Phase Processes & & \\
\hline Communication $[6,8,9,12,22,25,31]$ & $\begin{array}{l}\text { Monitoring progress toward } \\
\text { goals }[6,8,18,22]\end{array}$ & & \\
\hline Coaching [18] & Systems monitoring [18] & & \\
\hline Cognition $[12,25,31]$ & $\begin{array}{l}\text { Internal systems } \\
\text { monitoring }[18,22]\end{array}$ & & \\
\hline Shared cognition $[8,25,31]$ & $\begin{array}{c}\text { Environmental } \\
\text { monitoring }[8,18,22]\end{array}$ & & \\
\hline $\begin{array}{l}\text { Transactive memory } \\
\text { system }[8,12,25,31]\end{array}$ & $\begin{array}{l}\text { Team monitoring and backup } \\
\text { responses }[6,8,18,22,25,31]\end{array}$ & & \\
\hline Shared mental memory $[6,8,12]$ & $\begin{array}{c}\text { Coordination } \\
\text { activities }[6,9,12,18,22,25,31]\end{array}$ & & \\
\hline \multirow{2}{*}{\multicolumn{4}{|c|}{$\begin{array}{l}\text { Task-related features }[6,22,25,31] \\
\text { Team-related aspects }[6,22,25,31]\end{array}$}} \\
\hline & & & \\
\hline \multicolumn{4}{|l|}{ Culture $[8,9,12,22,23]$} \\
\hline \multicolumn{4}{|l|}{ Context [23] } \\
\hline \multicolumn{4}{|l|}{ Leadership structure $[6,12,22,25,31]$} \\
\hline \multicolumn{4}{|l|}{ Interpersonal phase processes } \\
\hline \multicolumn{4}{|l|}{ Conflict management $[18,25,31]$} \\
\hline \multicolumn{4}{|l|}{$\begin{array}{l}\text { Preemptive conflict } \\
\text { management [18] }\end{array}$} \\
\hline \multicolumn{4}{|l|}{ Reactive conflict management [18] } \\
\hline \multirow{2}{*}{\multicolumn{4}{|c|}{$\begin{array}{l}\text { Motivating/confidence } \\
\text { building }[18,22,25,31]\end{array}$}} \\
\hline & & & \\
\hline Effect management $[8,12,18,22]$ & & & \\
\hline
\end{tabular}

\section{MTS Effectiveness Model}

Multiteam systems are structured in a number of different ways. Typically, the best MTS structure is one that provides the greatest utility for the organization(s), while also being contextual, in that the structure is dependent upon the type of project and teams. Multiteam systems are generally structured so that they have both a shared leadership style as well as a hierarchical structure [34] that connects them to the larger organization. Shared leadership takes place at the team and MTS levels, while the organization's existing hierarchical structure takes place from the MTS level and higher (Figure 3). 


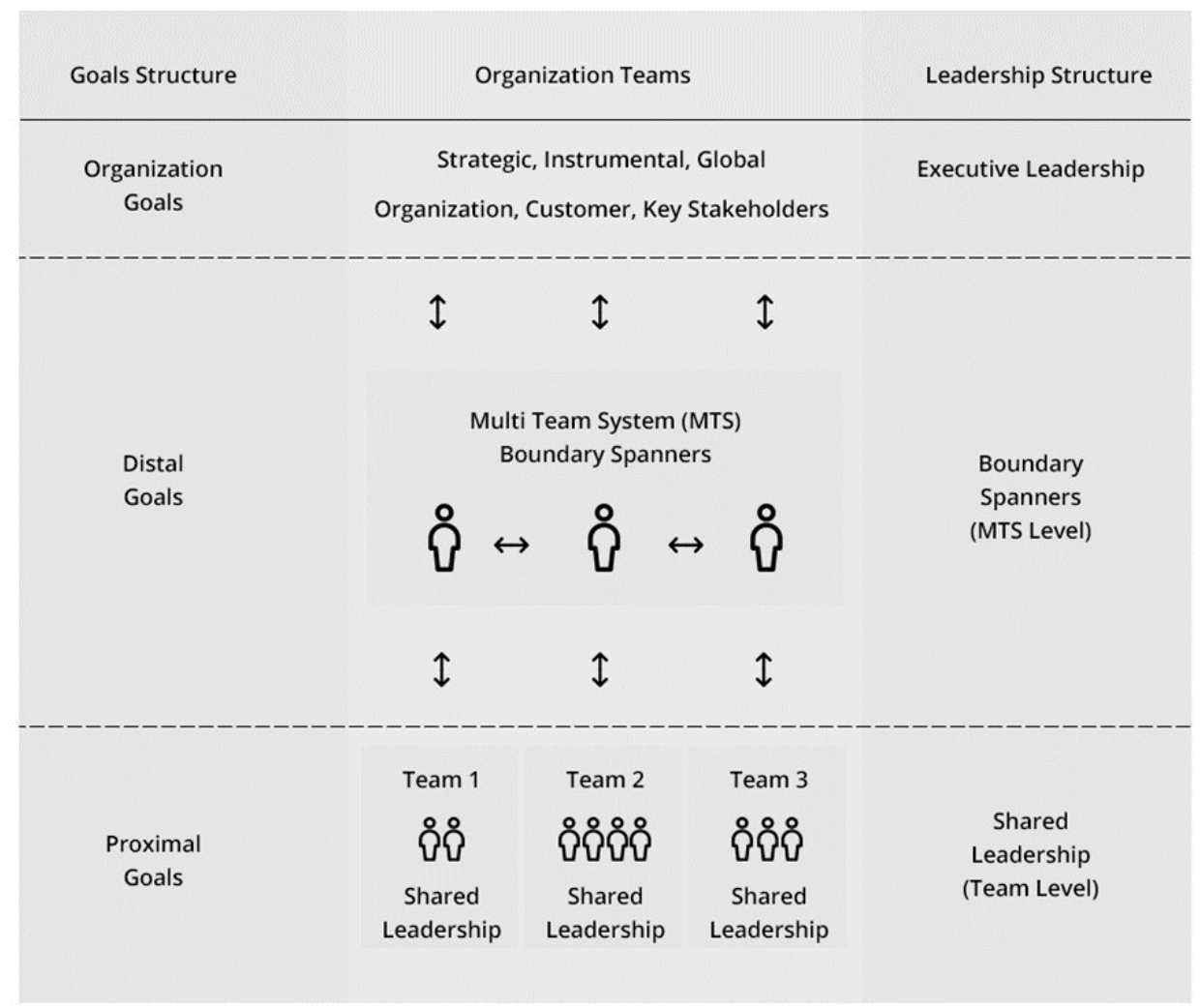

Figure 3. Multiteam system (MTS) leadership and goal structures.

For the model in the current study, the MTS is represented by functional leadership or a boundary spanner. Functional leadership views leader-team interactions, as opposed to traditional leadership models, which view leader-follower interactions. Functional leadership roles include building a vision, empowering agile execution, cultivating psychological safety, and developing shared mental models [35]. Similarly, boundary spanners have been defined as "organizational members whose primary role is to communicate extensively with constituencies in a relevant environment" [36] (p. 516). Iin this context, the environment is the MTS. The current study will use the term boundary spanner with the understanding that this role refers to both functional leadership theory and the roles identified in the literature for boundary spanners.

The role of the boundary spanner is primarily to communicate with the organization (typically the Executive Suite) and to direct the overall objectives of the MTS to the individual component teams within the MTS. The boundary spanner identifies the organizational goals, facilitates interactions among directors, assures that organizational resources are available when needed, and acts as a tiebreaker for the component teams when needed [34]. The boundary spanner takes on the leadership role, performing inter-team coordination activities that have been identified as being necessary for MTSs [37]. The healthcare industry, for example, found that leadership must "effectively coordinate processes across diverse professionals and teams" [37] (p. 1003) in MTSs to improve the capacity of the organization or hospital. Boundary spanners do not get involved with the inner workings of the component teams-these are managed by the team members through a shared leadership model. Moreover, boundary spanners are the main contacts for the organization and represent the component teams. A composite structure involving a boundary spanner, component teams, and individual team members constitutes an MTS.

One of the primary initial roles of the organization and the boundary spanner is to identify the MTS's objectives and to set the goals of the MTS. Once the MTS's goals have been identified, the number of component teams and the number of team members are assigned based on team member skills, knowledge, and experiences. The MTS's goals are then distributed appropriately to the component 
teams. In turn, each component team identifies their team goals and the tasks that will be required for them to achieve the MTS's goal. At the team level, the MTS's goal is the team's distal goal and the team's goals are called the team's proximal goals. By definition, MTSs include two or more teams "that interface directly and interdependently in response to environmental contingencies toward the accomplishment of collective goals" [24] (p. 290). In an MTS, each component team must have at least one distal goal that is shared with the MTS. The component team's distal goals could be the same as other component teams, but they are often different, each contributing to the overall objective of the MTS.

Extending Marks, Mathieu and Zaccaro's [18] temporal taxonomy, Table 2 includes the three dimensions and their sub-dimensions in relation to MTS and three levels of analysis (boundary spanner, component team, individual).

Table 2. MTS effectiveness temporal taxonomy.

\begin{tabular}{lccc}
\hline \multicolumn{1}{c}{ MTS Team Processes } & $\begin{array}{c}\text { MTS } \\
\text { (Boundary Spanner) }\end{array}$ & $\begin{array}{c}\text { Team } \\
\text { (Component Team) }\end{array}$ & Individual \\
\hline Transition & & & \\
$\quad$ Mission analysis formulation and & $\mathrm{X}$ & $\mathrm{X}$ & \\
planning & $\mathrm{X}$ & $\mathrm{X}$ & \\
$\quad$ Goal specification & $\mathrm{X}$ & $\mathrm{X}$ & $\mathrm{X}$ \\
$\quad$ Strategy formation & & $\mathrm{X}$ & $\mathrm{X}$ \\
Action & $\mathrm{X}$ & $\mathrm{X}$ & $\mathrm{X}$ \\
$\quad$ Monitoring progress toward goals & & $\mathrm{X}$ & \\
Systems monitoring & & & $\mathrm{X}$ \\
Team monitoring and backup responses & $\mathrm{X}$ & & \\
Coordination activities & $\mathrm{X}$ & $\mathrm{X}$ & \\
Interpersonal & & & \\
Conflict management & & & \\
Motivation and confidence building & & & \\
Effect management &
\end{tabular}

\subsection{Transition Processes}

The boundary spanner helps to identify the distal goal for each component team, while the component teams sets their own proximal goals, which are required to achieve the distal goal (mission analysis formulation and planning). The distal goal and strategy formation are influenced by various organizational factors (e.g., culture, diversity, policies) that are reflective of the MTS's goal; these factors affect each of the three transition stages. Each component team, with support from the boundary spanner, set their own proximal goals and identify the tasks required to achieve these goals (mission analysis formulation and planning, goal specification). The proximal goals are set at the team level, supported by the boundary spanner, under the shared leadership structure, as are their courses of action (strategy formulation).

\subsection{Action Processes}

As the boundary spanner is not usually involved with the daily workings of the component teams, they typically are not involved with the action processes, except when providing organizational resources as needed (systems monitoring). The responsibility of tracking individual tasks (monitoring progress toward goals) goes to the component team and team members. Team resources and external threats (systems monitoring) are tracked by the component team. Assisting team members through coaching, training, and other means (team monitoring and backup behavior) is conducted at the component team level, which influences individual team members. Lastly, team members and the component team as a whole are responsible for scheduling and timing their activities and tasks (coordination), while the boundary spanner must be aware of this coordination in order to align the team's coordination with the MTS's coordination. 


\subsection{Interpersonal Processes}

All levels are involved in the interpersonal processes. Resolving conflict within teams and between teams (conflict management) involves the boundary spanner. Maintaining a sense of membership to the MTS is partially the role of the boundary spanner, whereas membership within each component team is enhanced by each component team (motivation and confidence building). Under the shared leadership model, the component team and individual component team members monitor and manage one another's emotions (effect management).

\subsection{The MTS Effectiveness Model}

Accounting for the temporal processes (transition, action, interpersonal), we compiled the team effectiveness components that were presented earlier into a synthesized framework, which includes the three levels of analysis that are relevant to MTSs (boundary spanner, component team, individual). Table 3 provides our new comprehensive MTS effectiveness model. This synthesized model accounts for temporal processes, along with teamwork, taskwork, and team performance improvement components at each level, meeting the calls from researchers to expand upon the temporal model and to include teamwork [6]. Table 3 illustrates our new comprehensive MTS effectiveness model.

Table 3. MTS effectiveness model.

\begin{tabular}{|c|c|c|c|}
\hline Temporal Process & MTS (Boundary Spanner) & Team (Component Team) & Individual \\
\hline \multicolumn{4}{|l|}{ Transition } \\
\hline $\begin{array}{l}\text { Mission analysis } \\
\text { formulation and } \\
\text { planning }\end{array}$ & $\begin{array}{l}\text { Closed-loop communication, duration, } \\
\text { genesis, hierarchical arrangement, network, } \\
\text { organizational structure }\end{array}$ & $\begin{array}{l}\text { Mission analysis, planning, } \\
\text { team mission }\end{array}$ & \\
\hline Goal specification & $\begin{array}{l}\text { National culture, organizational culture, } \\
\text { organizational diversity, } \\
\text { organizational goals }\end{array}$ & $\begin{array}{l}\text { Accurate problem models, task } \\
\text { characteristics, team goal commitment }\end{array}$ & \\
\hline Strategy formation & $\begin{array}{l}\text { Collaboration with interagency partners, } \\
\text { communication structure, functional } \\
\text { diversity, geographically dispersion of } \\
\text { teams, mode of communication, } \\
\text { organizational diversity, organizational } \\
\text { policies, power distribution, stage of } \\
\text { development, temporal orientation, } \\
\text { training, transformation of development }\end{array}$ & Developing strategy, finishing & \\
\hline \multicolumn{4}{|l|}{ Action } \\
\hline $\begin{array}{l}\text { Monitoring progress } \\
\text { toward goals }\end{array}$ & & $\begin{array}{l}\text { Cue strategy associations, helping, } \\
\text { mutual performance monitoring, } \\
\text { problem detection, workload sharing }\end{array}$ & $\begin{array}{l}\text { Leadership (shared), } \\
\text { task-related assertiveness }\end{array}$ \\
\hline Systems monitoring & Resources & Gathering information & \\
\hline $\begin{array}{l}\text { Teams monitoring and } \\
\text { backup responses }\end{array}$ & & $\begin{array}{l}\text { Adapting, backup supporting } \\
\text { behavior, helping, learning from } \\
\text { team's best member, team orientation, } \\
\text { workload sharing }\end{array}$ & Openness to change \\
\hline Coordination activities & & $\begin{array}{l}\text { Coordination horizontal, implicit } \\
\text { coordination strategies, } \\
\text { interdependence, planning, } \\
\text { team autonomy }\end{array}$ & $\begin{array}{l}\text { Individual roles, planning, } \\
\text { self-management skills, } \\
\text { work experience }\end{array}$ \\
\hline \multicolumn{4}{|l|}{ Interpersonal } \\
\hline Conflict management & Conflict resolution & & \\
\hline $\begin{array}{l}\text { Motivation and } \\
\text { confidence building }\end{array}$ & Motivation of others, rewards & & \\
\hline Effect management & & $\begin{array}{l}\text { Mutual trust, peer control, shared } \\
\text { mental models (MTS), social identity, } \\
\text { team cohesion, team empowerment, } \\
\text { team learning orientation, team } \\
\text { potency, team psychological safety, } \\
\text { team satisfaction }\end{array}$ & $\begin{array}{l}\text { Individual autonomy, } \\
\text { general skills, trust }\end{array}$ \\
\hline
\end{tabular}

\subsection{MTS Team Effectiveness Formula}

Expanding upon the team effectiveness formula for individual teams (Formula (2)), a team effectiveness formula for MTS is proposed here. The effectiveness of an MTS becomes more complicated 
compared to the team effectiveness of an individual team. Adding a new level of analysis (MTS) expands the formula into a multilevel formula, which includes the component teams at a lower level of analysis and the MTS at a higher level of analysis. The MTS team effectiveness formula is composed of two separate formulas, the first for the lower level components (component team level) and the second for the higher-level components (MTS). Formula (3) presents the lower-level formula and Formula (4) provides the higher-level formula; both are comprised of an MTS team effectiveness formula:

$$
\begin{gathered}
\text { MTS TE }(\text { higher level })=(C-C)+(C-B S)+(\text { Pmts })+(C \text { Vmts })+ \\
\text { SUM } \sum[\text { TE }(\text { lower level })]
\end{gathered}
$$

$$
\begin{gathered}
\text { SUM } \sum[T E(\text { lower level })]=\text { Component Team } 1[(T W+I P)+T K(T P+A P)+P F+C V]+ \\
\ldots+\text { Component Team } n[(T W+I P)+T K(T P+A P)+P F+C V]
\end{gathered}
$$

Multiteam system effectiveness requires interactions between the component teams that make up the MTS, as well as interactions between each component team and the boundary spanner. Here, MTS effectiveness should account for component team to component team interactions $(C-C)$, component team to boundary spanner interactions $(C-B S)$, performance at the MTS level (Pmts), and customer value at the MTS level (CVmts), plus the aggregate for the component teams' effectiveness measure. The formulas (higher level and lower level) presented here for MTS team effectiveness (Formulas (3) and (4)) are presented in the most basic manner. These formulas could be depicted in a multilevel formula format with subscripts for component teams and superscripts for the MTS, but for their initial presentation in the current study, we decided to keep the formula in its simplest form. The formulas presented in the current article will need to be tested and refined in future research studies, as their presentation in the current article are at the conceptual level.

The interactions described above are depicted in Figure 4. Coordination is critical between each component team $(C-C)$, along with the much-needed coordination activities between each component team and the boundary spanner $(C-B S)$. Prior research has supported that inter-team coordination explains MTS performance [37]. At the higher level of the multiteam system, team effectiveness becomes dependent upon the interactions between the component teams and the boundary spanner, each informed by the transition, action, and interpersonal processes (as shown in Table 3). Effective coordination of the components presented in the current research can aid in effectively managing the complexity and systemic factors of a multiteam system. However, additional research is needed to determine more precisely how the inputs into the component teams and coordination within the multiteam system can be trained, coordinated, and investigated by scholars, practitioners, and researchers.

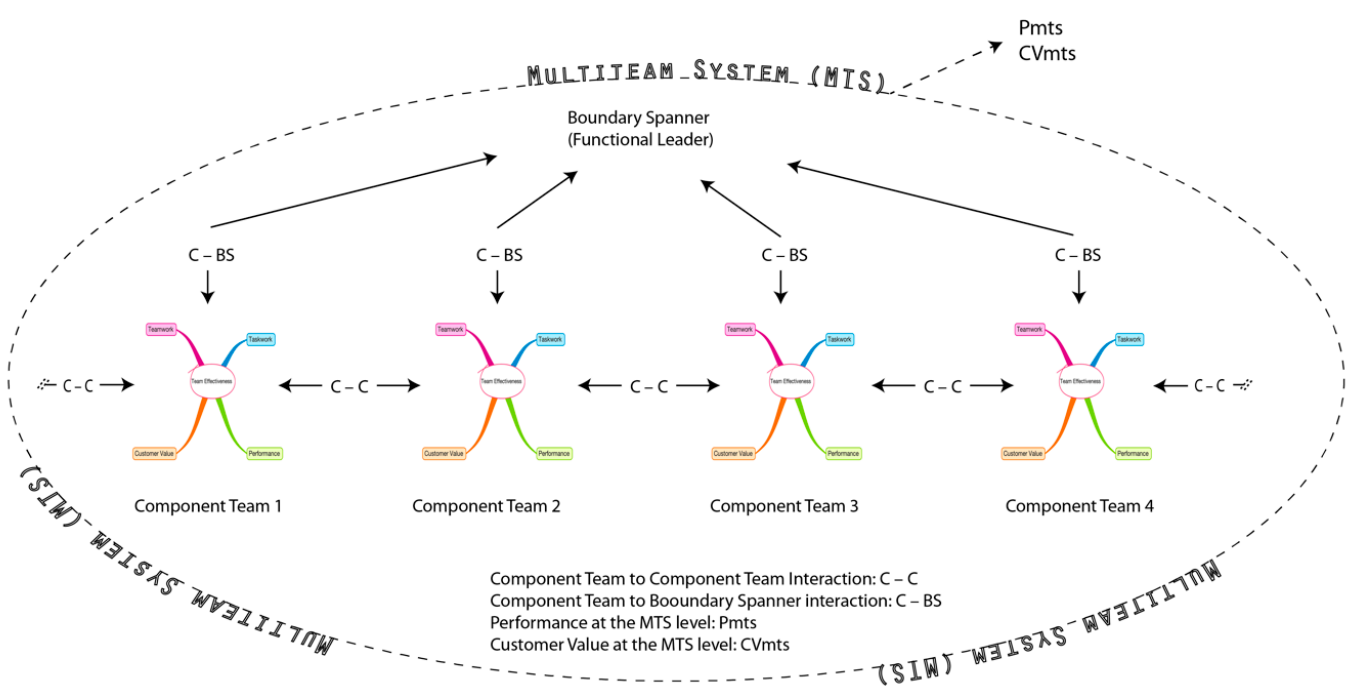

Figure 4. Team effectiveness components coordination within a multiteam system (MTS). 


\section{Discussion}

The purpose of this study was to synthesize the literature that presented team effectiveness models and to develop a new team effectiveness model that included MTSs, in order to provide a new level of analysis. This new MTS team effectiveness model differentiates team characteristics at each level of analysis (MTS, component team, individual) and for each temporal process (transition, action, interpersonal). Our contributions to the team science and systems literature include the new MTS team effectiveness model and the presentation of team effectiveness formulas for individual teams and for MTSs.

\subsection{Team Training-TeamSTEPPS}

Team training is contextual and works best when all team members train together while working on real-world problems. In situ training must address an organization's contextual conditions before being able to aid and support the teams that are to be trained. The Team Strategies and Tools to Enhance Performance and Patient Safety (TeamSTEPPS) [38] program/training is designed around identifying the most essential characteristics/competencies for the team's environment. For example, in medical healthcare, the following teamwork competencies were identified for their TeamSTEPPS training: team leadership, mutual performance monitoring, backup behavior, adaptability, shared mental models, and communication [38] (https://www.ahrq.gov/teamstepps/index.html). Training was then designed and focused around these critical teamwork skills and competencies.

Team training is most effective when it is aligned with the organizational objectives and has strong executive sponsorship; this highlights the importance of the new role of the boundary spanner. The same success that has been experienced in healthcare fields using the TeamSTEPPS training can, and should, be realized in other industries. Training should be designed using the MTS training hierarchy shown in Figure 5.

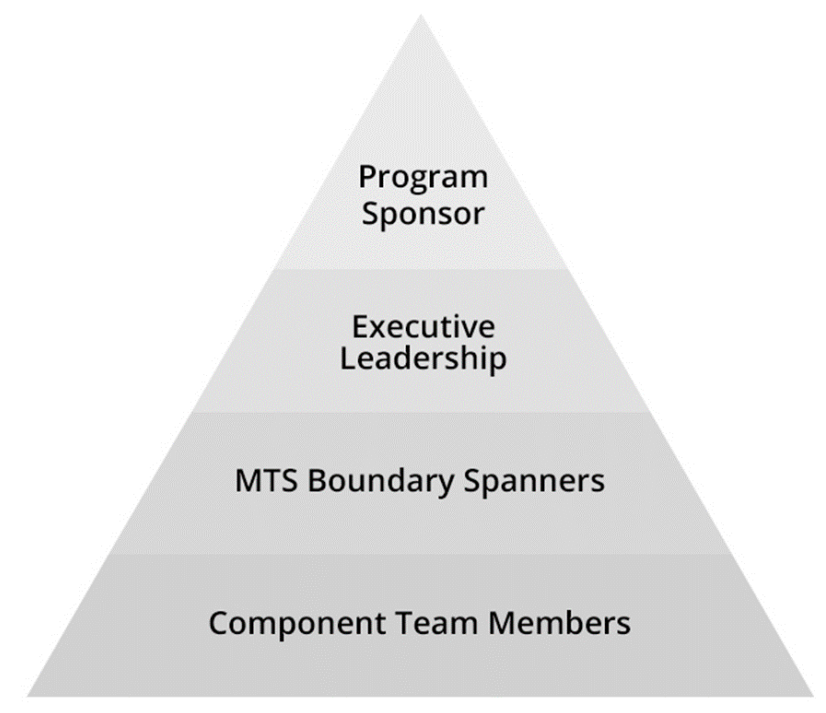

Figure 5. MTS training hierarchy.

The MTS training hierarchy includes the following components:

1. Program Sponsor: the program sponsor should be an executive who is well respected, senior in the organization, and aligned with the benefits that the MTS could yield, both professionally and personally, for the executive. Their role is to be a spokesperson and clear hurdles for the implementation team;

2. Executive Leadership: the Executive Leadership is responsible for the strategic direction in times of "ambiguity, complexity, and information overload" [39] (p. 516) and for strategic leadership. 
The Executive Leadership must also be capable of "identify[ing] strategic and tactical goals while monitoring team outcomes and the environment" [40] (p. 747) and for instrumental leadership. Lastly, Executive Leadership must also be capable of developing a global mindset for leaders, teams, and followers [41] (p. 121) and for global leadership. Executive Leadership must operate within a hybrid leadership model, utilizing components from strategic, instrumental, and global leadership models that have been shown to work well in complexity and with teams;

3. MTS Boundary Spanners: the selection of the MTS boundary spanner is necessary for organizations to achieve high levels of MTS effectiveness. Boundary spanners are unique individuals who "relate the internal organization to the external environment" [42] (p. 512). The boundary spanner implements the scaffolding role for the MTS and the component teams by being "an active agent who provides support for organizational members while knowledge practices and relationships are transferred to and transformed within an organization" [43] (p. 512);

4. Component Team Members: self-leadership, self-efficacy, and project management skills should begin the training at an individual level. This would then transition into shared leadership at a team level. Shared leadership training covers training in areas of transactional and transformational leadership, directive leadership, and empowering leadership [43]. The general idea is that leadership will vary as the context and environment changes, i.e., leadership is contextual. For example, transactional leadership has been shown to be more effective in stable environments where innovation is only incremental. In contrast, transformational leadership aids in improving innovation and effectiveness [43].

A multiteam system is a transformational approach to management and a top-down approach for the MTS was designed in this paper for successful deployment within an organization, by starting out first as a pilot and then gaining momentum by demonstrating success.

Before embarking on the MTS training delivery, the training team should follow the MTS training methodology (Figure 6), which consists of the following six components:

1. As Is Assessment: the team should review the strategic vision and goals (organizational, distal and proximal), as well as perform surveys and interviews at all levels of the organization to gain an understanding of the situation in the organization. This will also lead to the development of the key metrics that need to be measured for the success of the program. The exercise will help the team define key success factors in order to ensure that the MTS implementation is successful, which then need to be reviewed with the sponsor for executive support;

2. Executive Leadership: with the support of the executive sponsor, the key business reasons for implementing the MTS model should be reviewed with the executive leadership team. They should also understand the fundamentals of the MTS model, with clear expectations from the team, as well as their role in making the transformation successful;

3. MTS Boundary Spanners (Champions): the MTS Boundary Spanners' role spans executives, component teams and engages with other boundary spanners. It is very important that they are the true champions of the MTS model and they should go through an extensive training program together, as a team. By taking the training together, they will not only understand the MTS, accounting for the temporal processes of transition, action and interpersonal processes, but also building a relationship that allows them to work with each other to share experiences and success stories and to overcome hurdles together as a team while implementing the MTS model;

4. Staff Training: this training for component teams should be conducted by MTS Boundary Spanners, with a focus on Transition, Action and Interpersonal processes to enhance the skills of the team;

5. Continuous Measurement: the MTS model is based on the premise of continuous improvement, which is aligned with the key metrics that the organization is working to achieve. The training process should review the key metrics on a quarterly and biannual basis to gauge current results, while establishing future goals in collaboration with the team; 
6. Training Support: a support structure should be put into place that allows for the initial support of the MTS Boundary Spanners. Development of the boundary spanner leadership role must involve training of the roles and responsibilities in addition to the initial deployment of the leadership role before the MTS can be assimiliated into the culture of the organization.

Training content delivery is recommended to start at the individual level for all members of the MTS (Boundary Spanner and Component Team). The team members and the boundary spanner need to have their distal and proximal goals in alignment after this training. This alignment can be developed and supported through the processes provided in the TeamSTEPPS training program in order to identify the critical competencies listed in Table 3.

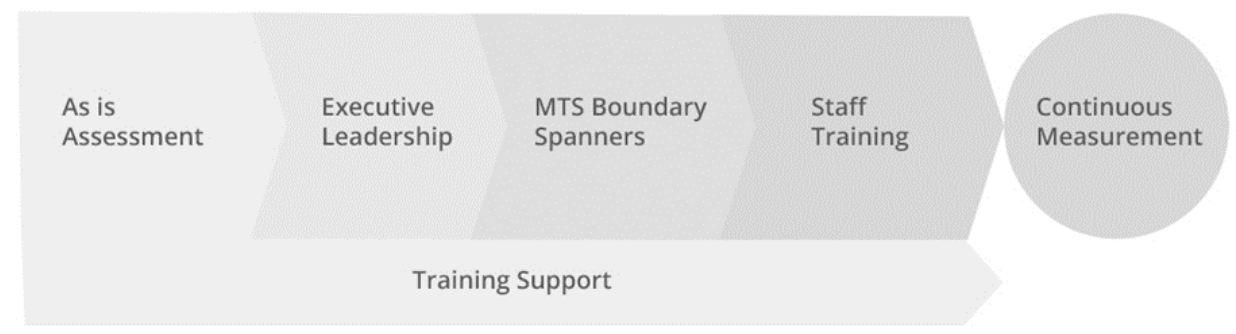

Figure 6. MTS training support.

\subsection{Team Evaluation}

This new framework provides a tool for practitioners and managers to use when assessing MTSs. This tool identifies which characteristics should be assessed based on the level that is being evaluated. It also identifies different characteristics that should take place depending on the dimension that the team is operating in (action or transitional). This model can also be treated as a dynamic model for organizations and MTSs to utilize. Dynamic models refer to an organization's, or an MTS's, unique capabilities for creating and changing routines and resources as required when adapting to external threats [44]. The new MTS team effectiveness model provides a dynamic model that explains how MTS's evolve over time (temporal dimension) and which capabilities aid in this adaptation when environmental threats are being experienced. This provides managers with the tools to better implement adaptable characteristics into their organizational systems, especially those structured using an MTS.

Aside from providing a tool to aid managers, practitioners, and researchers, the new MTS team effectiveness model could also be utilized when assessing teams and MTSs. A number of the team effectiveness measures found in the literature have either not been validated or lack evidence regarding the relationships between the measured factors [25]. Although the new MTS team effectiveness model has been composed using current models and frameworks from the literature, therefore meeting the evidence component, a measure for MTS team effectiveness still needs to be developed. The model presented in this research provides a starting point for developing a multilevel MTS team effectiveness instrument, meeting calls for the inclusion of "complex models to represent emergent states" [45] (p. 690) and for the development of more multilevel models.

\subsection{Aids for Future Research Efforts}

This new MTS team effectiveness model also offers utility in research by providing a tool that could be used for newer event or pattern type research methods. Traditional correlational research methods that assess a single point in time, while useful in certain circumstances, have not served multilevel phenomena such at MTSs very well. When studying multilevel and complex systems, such as in MTSs, researchers have recommended analyzing patterns and sequences rather than correlations. Morgeson, Mitchell, and L'iu [46] stated that this was surprising when referring to the lack of viewing events and the role they play in organizational phenomena. For example, Schecter et al. [47] recommended analyzing "patterns of event-based processes" (p. 1) such as intragroup interactions, 
intergroup interactions, mission analysis formations, team backup responses, or any of the other characteristics listed in this new MTS team effectiveness model presented in Table 3. The characteristics in this new MTS team effectiveness model have been divided by levels of analysis as well as by temporal dimensions, allowing researchers to focus on different events that occur across these temporal dimensions. This MTS team effectiveness model could be utilized as a tool to aid in future research that focuses on events for MTSs.

Whereas the characteristics in each of the cells for the new MTS team effectiveness model could be classified as features (e.g., brainstorming, conflict resolution and the motivations of others), the addition of the temporal dimensions extends these characteristics to potential events. This distinction extends the utility of the new MTS team effectiveness model in that it provides a tool to develop not only traditional feature-based theories, but also to aid in developing event-based theories. Events, according to Morgeson, Mitchell, and Liu [46], are "discrete and bounded in space and time" (p. 516). Event-based theories describe how events change over time, longitudinally, providing better explanations of change and emergence. Furthermore, theorizing how these events take place over time (temporal dimensions: transition, action, interpersonal) as well as across different levels (MTSs, component teams, individuals), as presented in the new MTS team effectiveness model, increases the potential utility of this model.

\section{Conclusions}

Technological advances have provided organizations and institutions with the tools to address complex problems. However, technology alone is unable to tackle today's complex problems. Today, organizations are geographically dispersed across countries and nations. The problems faced are local, national, and global. The context of these types of problems continue to change; the complex problems that organizations and institutions are challenged with today are real-world problems, requiring dynamic problem-solving techniques to be implemented. Teams within teams, utilizing the benefits of new technological advancements, who are able to adapt as problems change are creating a new mid-level organizational structure, a hierarchical network [48], a shared leadership plus hierarchy [34], also known as MTSs.

Understanding the inner workings of teams and MTSs benefits managers, practitioners, and researchers in that these types of structures are the ones they will encounter in the workplace moving forward. Having a better understanding of MTS team effectiveness benefits future research efforts as more MTSs are implemented to address both organizational and societal problems [45]. Identifying with, and being able to differentiate between, teamwork and taskwork will aid in managing, evaluating, and researching MTSs. This differentiation better identifies the emergent constructs for teams and MTSs that could be the focus of future research. The MTS effectiveness model presented in the current article aids managers, practitioners, and researchers by providing a tool that identifies relevant characteristics of MTSs at each of the three temporal process dimensions [18] for each level of analysis (individuals, component teams, teams of directors, facilitators). This study advances research in the area of team science and MTSs in that it presents a new MTS effectiveness model that provides utility for organizations, as well as providing opportunities for future research.

Author Contributions: Conceptualization, J.T., R.B., Z.A., and N.T.; writing-draft preparation, review, and editing, J.T., R.B., and Z.A. All authors have read and agreed to the published version of the manuscript.

Funding: This research received no external funding.

Conflicts of Interest: The authors declare no conflict of interest.

\section{References}

1. Guzzo, R.A.; Dickson, M.W.; Teams in organizations. Recent research on performance and effectiveness. Annu. Rev. Psychol. 1996, 47, 307-338. [CrossRef] [PubMed]

2. Kozlowski, S.W.J.; Ilgen, D.R. Enhancing the effectiveness of work groups and teams. Psychol. Sci. Work Groups Teams 2006, 7, 77-124. [CrossRef] 
3. Driskell, J.E.; Salas, E.; Driskell, T. Foundations of teamwork and collaboration. Am. Psychol. 2018, 73, 334-348. [CrossRef]

4. Cohen, S.G.; Bailey, D.E. What makes teams work: Group effectiveness research from the shop floor to the executive suite. J. Manag. 1997, 23, 239-290. [CrossRef]

5. Mathieu, J.E.; Gallagher, P.T.; Domingo, M.A.; Klock, E.A. Embracing complexity: Reviewing the past decade of team effectiveness research. Annu. Rev. Organ. Psychol. Organ. Behav. 2019, 6, 17-46. [CrossRef]

6. Salas, E.; Sims, D.E.; Burke, S.C. Is there a "big five” in teamwork? Small Group Res. 2005, 36, 555-599. [CrossRef]

7. Kamphuis, W.; Essens, P.J.M.D.; Houttuin, K.; Gaillard, A.W.K. PLATT: A flexible platform for experimental research on team performance in complex environments. Behav. Res. Methods 2010, 42, 739-753. [CrossRef]

8. Ilgen, D.R.; Hollenbeck, J.R.; Johnson, M.; Jundt, D. Teams in organizations: From Input-Process-Output to IMOI models. Annu. Rev. Psychol. 2005, 56, 517-543. [CrossRef]

9. Zaccaro, S.J.; Marks, M.A.; Dechurch, L.A. Multiteam systems: An introduction. In Multiteam Systems: An Organization form for Dynamic and Complex Environments; Zaccaro, S.J., Marks, M.A., Dechurch, L.A., Eds.; Routledge: New York, NY, USA, 2012; pp. 3-32.

10. DeChurch, L.A.; Marks, M.A. Leadership in multiteam systems. J. Appl. Psychol. 2006, 91, 311-329. [CrossRef]

11. DeChurch, L.A.; Burke, C.S.; Shuffler, M.L.; Lyons, R.; Doty, D.; Salas, E. A historiometric analysis of leadership in mission critical multiteam environments. Leadersh. Q. 2011, 22, 152-169. [CrossRef]

12. Shuffler, M.L.; Jimenez-Rodriguez, M.; Kramer, W.S. The science of multiteam systems: A review and future research agenda. Small Group Res. 2015, 46, 659-699. [CrossRef]

13. Gladstein, D.L. Groups in context: A model of task group effectiveness. Adm. Sci. Q. 1984, 29, 499-517. [CrossRef]

14. Bell, S.T.; Brown, S.G.; Outland, N.B.; Abben, D.R. Critical Team Composition Issues for Long-Distance and Long-Duration Space Exploration: A Literature Review, and Operational Assessment and Recommendations for Practice and Research; NASA: Houston, TX, USA, 2015.

15. Christodoulou, I.; Babalis, D.; Gymnopoulos. Building teamwork in hospitals: Detecting the situation in an example from Greece. Int. J. Health Sci. 2008, 1, 74-77.

16. Mathieu, J.E.; Maynard, T.M.; Rapp, T.; Gilson, L. Team effectiveness 1997-2007: A review of recent advancements and a glimpse into the future. J. Manag. 2008, 34, 410-476. [CrossRef]

17. Hackman, J.R. Collaborative Intelligence: Using Teams to Solve Hard Problems; Berrett-Koehler: San Francisco, CA, USA, 2011.

18. Marks, M.A.; Mathieu, J.E.; Zaccaro, S.J. A temporally based framework and taxonomy of team processes. Acad. Manag. Rev. 2001, 26, 356-376. [CrossRef]

19. Martins, L.L.; Gilson, L.L.; Maynard, T.M. Virtual teams: What do we know and where do we go from here? J. Manag. 2004, 30, 805-835. [CrossRef]

20. Turner, J.R.; Baker, R. Team emergence leadership development and evaluation: A theoretical model using complexity theory. J. Inf. Knowl. Manag. 2017, 16, 17. [CrossRef]

21. Lichtenstein, B.B.; Uhl-Bien, M.; Marion, R.; Seers, A.; Orton, J.D.; Schreiber, C. Complexity leadership theory: An interactive perspective on leading in complex adaptive systems. Emerg. Complex. Org. 2006, 8, 2-12.

22. Magpili, N.C.; Pazos, P. Self-managing team performance: A systematic review of multilevel input factors. Small Group Res. 2018, 49, 3-33. [CrossRef]

23. Dihn, J.V.; Salas, E. Factors that influence teamwork. In The Wiley Blackwell Handbook of the Psychology of Team Working and Collaborative Processes; Salas, E., Rico, R., Passmore, J., Eds.; John Wiley \& Sons: Malsen, MA, USA, 2017; pp. 15-41.

24. Mathieu, J.E.; Marks, M.A.; Zaccaro, S.J. Multi-team systems. In The Handbook of Industrial, Work and Organizational Psychology; Anderson, N., Ones, D.S., Sinangil, H.K., Viswesvaran, C., Eds.; SAGE: London, UK, 2001; Volume 2, pp. 289-313.

25. Marlow, S.; Bisbey, T.; Lacerenza, C.; Salas, E. Performance measures for health care teams: A review. Small Group Res. 2018, 49, 306-356. [CrossRef]

26. Kozlowski, S.W.J.; Grand, J.A.; Baard, S.K.; Pearce, M. Teams, teamwork, and team effectiveness: Implications for human system integration. In The Handbook of Human Systems Integration; Boehm-Davis, D., Durso, F., Lee, J., Eds.; APA: Washington, DC, USA, 2015.

27. Salas, E.; Cooke, N.J.; Rosen, M.A. On teams, teamwork, and team performance: Discoveries and developments. Hum. Factors 2008, 50, 540-547. [CrossRef] [PubMed] 
28. Marks, M.A.; DeChurch, L.A.; Mathieu, J.E.; Panzer, F.J.; Alonso, A. Teamwork in multiteam systems. J. Appl. Psychol. 2005, 90, 964-971. [CrossRef] [PubMed]

29. McGrath, J.E.; Arrow, H.; Berdahl, J.L. The study of groups: Past, present, and future. Personal. Soc. Psychol. Rev. 2000, 4, 95-105. [CrossRef]

30. Weaver, S.J.; Feitosa, J.; Salas, E.; Seddon, R.; Vozenilek, J.A. The theoretical drivers and models of team performance and effectiveness for patient safety. In Improving Patient Safety Through Teamwork and Team Training; Salas, E., Frush, K., Eds.; Oxford University Press: New York, NY, USA, 2013; pp. 3-26.

31. Salas, E.; Rosen, M.A.; Burke, C.S.; Goodwin, G.F. The wisdom of collectives in organizations: An update of the teamwork competencies. In Team Effectiveness in Complex Organizations; Salas, E., Goodwin, G.F., Burke, C.S., Eds.; Taylor \& Francis: New York, NY, USA, 2009; pp. 39-79.

32. Devine, D.J. A review and integration of classification systems relevant to teams in organizations. Group Dyn. Theory Res. Pract. 2002, 6, 291-310. [CrossRef]

33. Rico, R.; Sanchez-Manzanares, M.; Gil, F.; Gibson, C. Team implicit coordination processes: A team knowledge-based approach. Acad. Manag. Rev. 2008, 33, 163-184. [CrossRef]

34. Goodwin, G.F.; Essens, P.J.M.D.; Smith, D. Multiteam systems in the public sector. In Multiteam Systems: An Organization form for Dynamic and Complex Environments; Zaccaro, S.J., Marks, M.A., Dechurch, L.A., Eds.; Routledge: New York, NY, USA, 2012; pp. 53-78.

35. Edmondson, A.C.; Harvey, J.-F. Extreme Teaming: Lessons in Complex, Cross-Sector Leadership; Emerald Publishing Limited: Bingley, UK, 2017.

36. Connaughton, S.; Shuffler, M.; Goodwin, G.F. Leading distributed teams: The communicative constitution of leadership. Milit. Psychol. 2011, 23, 502-527. [CrossRef]

37. Jones, K.J.; Skinner, A.; Venema, D.; Crowe, J.; High, R.; Kennel, V.; Allen, J.; Reiter-Palmon, R. Evaluating the use of multiteam systems to manage the complexity of inpatient falls in rural hospitals. Health Serv. Res. 2019, 54, 994-1006. [CrossRef]

38. Alonso, A.; Baker, D.P.; Holtzman, A.; Day, R.; King, H.; Toomey, L.; Salas, E. Reducing medical error in the military health system: How can team training help? Hum. Resour. Manag. Rev. 2006, 16, 396-415. [CrossRef]

39. Boal, K.B.; Hooijberg, R. Strategic leadership research: Moving on. Leadersh. Q. 2000, 11, 515-549. [CrossRef]

40. Antonakis, J.; House, R.J. Instrumental leadership: Measurement and extension of transformationaltransactional leadership theory. Leadersh. Q. 2014, 25, 746-771. [CrossRef]

41. Bird, A.; Mendenhall, M.E. From cross-cultural management to global leadership: Evolution and adaptation. J. World Bus. 2016, 51, 115-126. [CrossRef]

42. Roberts, M.J.D.; Beamish, P.W. The scaffolding activities of international returnee executives: A learning based perspective of global boundary spanning. J. Manag. Stud. 2017, 54, 511-539. [CrossRef]

43. Cox, J.F.; Pearce, C.L.; Perry, M.L. Toward a model of shared leadership and distributed influence in the innovation process: How shared leadership can enhance new product development team dynamics and effectiveness. In Shared Leadership: Reframing the Hows and Whys of Leadership; Pearce, C.L., Conger, J.A., Eds.; Sage: Thousand Oaks, CA, USA, 2003; pp. 48-76.

44. Kurtmollaiev, S.; Pedersen, P.E.; JFjuk, A.; Kvale, K. Developing managerial dynamic capabilities: A quasi-experimental field study of the effects of design thinking training. Acad. Manag. Learn. Educ. 2018, 17, 184-202. [CrossRef]

45. Coultas, C.W.; Driskell, T.; Burke, S.C.; Salas, E. A conceptual review of emergent state measurement: Current problems, future solutions. Small Group Res. 2014, 45, 371-703. [CrossRef]

46. Morgeson, F.P.; Mitchell, T.R.; Liu, D. Event system theory: An event-oriented approach to the organizational sciences. Acad. Manag. Rev. 2015, 40, 515-537. [CrossRef]

47. Schecter, A.; Pilny, A.; Leung, A.; Poole, M.S.; Contractor, N. Step by step: Capturing the dynamics of work team process through relational event sequences. J. Organ. Behav. 2017, 38, 1-19. [CrossRef]

48. Moynihan, D.P. From Forest Fires to Hurricane Katrina: Case Studies of Incident Command Systems; IBM Center for the Business of Government: Washington, DC, USA, 2007.

(C) 2020 by the authors. Licensee MDPI, Basel, Switzerland. This article is an open access article distributed under the terms and conditions of the Creative Commons Attribution (CC BY) license (http://creativecommons.org/licenses/by/4.0/). 